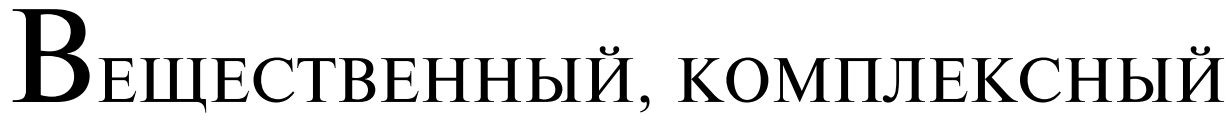 И ФУНКЦИОНАЛЬНЫЙ АНАЛИЗ
}

\section{Real, COMplex}

AND FUNCTIONAL ANALYSIS

УДК 517.938

\section{УПАКОВОЧНЫЕ РАЗМЕРНОСТИ БАССЕЙНОВ, ПОРОЖАЕННЫХ РАСПРЕАЕАЕНИЯМИ НА КОНЕЧНОМ АЛФАВИТЕ}

\author{
В. И. БАХТИН ${ }^{1)}$, Б. САДОК ${ }^{2)}$ \\ ${ }^{1)}$ Белорусский государственный университет, пр. Независимости, 4, 220030, г. Минск, Беларусь \\ 2) Люблинский католический университет им. Иоанна Павла II, \\ ал. Раилавищкая, 14, 20-950, г. Люблин, Польша
}

Рассматривается пространство бесконечных сигналов, составленных из букв конечного алфавита. Каждый сигнал порождает последовательность эмпирических мер на алфавите и отвечающее этой последовательности предельное множество. Все пространство сигналов разбивается на узкие бассейны, состоящие из сигналов с одинаковыми предельными множествами для последовательности эмпирических мер. Для каждого узкого бассейна вычисляется его упаковочная размерность. Кроме того, рассчитываются упаковочные размерности бассейнов двух других типов, определяемых в терминах предельного поведения эмпирических мер.

Ключевые слова: упаковочная размерность; эмпирическая мера; бассейн вероятностной меры.

\section{Образец цитирования:}

Бахтин ВИ, Садок Б. Упаковочные размерности бассейнов, порожденных распределениями на конечном алфавите. Журнал Белорусского государственного университета. Математика. Информатика. 2021;2:6-16 (на англ.). https://doi.org/10.33581/2520-6508-2021-2-6-16
For citation:

Bakhtin VI, Sadok B. Packing dimensions of basins generated by distributions on a finite alphabet. Journal of the Belarusian State University. Mathematics and Informatics. 2021;2:6-16. https://doi.org/10.33581/2520-6508-2021-2-6-16

\section{Ав торы:}

Виктор Иванович Бахтин - доктор физико-математических наук, профессор; профессор кафедры функционального анализа и аналитической экономики механико-математического факультета.

Бруно Садок - лектор кафедры теории вероятностей и статистики факультета естественных наук и наук о здоровье.

\author{
Authors: \\ Victor I. Bakhtin, doctor of science (physics and mathematics), \\ full professor; professor at the department of functional analy- \\ sis and analytical economics, faculty of mechanics and mathe- \\ matics. \\ bakhtin@tut.by \\ https://orcid.org/0000-0001-5782-5378
}

Bruno Sadok, lecturer at the department of probability theory and statistics, faculty of natural sciences and health.

bruno.bonitas@gmail.com 


\title{
PACKING DIMENSIONS OF BASINS GENERATED BY DISTRIBUTIONS ON A FINITE ALPHABET
}

\author{
V. I. BAKHTIN ${ }^{\mathrm{a}}$, B. SADOK ${ }^{\mathrm{b}}$ \\ ${ }^{a}$ Belarusian State University, 4 Niezaliežnasci Avenue, Minsk 220030, Belarus \\ ${ }^{\mathrm{b}}$ John Paul II Catholic University of Lublin, 14 Racławickie Alley, Lublin 20-950, Poland \\ Corresponding author: V.I.Bakhtin (bakhtin@tut.by)
}

\begin{abstract}
We consider a space of infinite signals composed of letters from a finite alphabet. Each signal generates a sequence of empirical measures on the alphabet and the limit set corresponding to this sequence. The space of signals is partitioned into narrow basins consisting of signals with identical limit sets for the sequence of empirical measures and for each narrow basin its packing dimension is computed. Furthermore, we compute packing dimensions for two other types of basins defined in terms of limit behaviour of the empirical measures.
\end{abstract}

Keywords: packing dimension; empirical measure; basin of a probability measure.

\section{Introduction}

Signals of infinite length composed of letters from a finite alphabet may be classified in accordance with limit behaviour of generated by these signals empirical measures on the alphabet. It turns out that different classes of signals (which we call basins) have a sophisticated fractal structure, and the most adequate quantitative characteristic for their description is fractal dimension. For the first time Hausdorff dimensions of certain basins were calculated by Billingsley in [1;2]. In [3] it was suggested to consider the so-called narrow basins, that are distinguished among other types of basins by the fact that they form a partition of the space of all infinite signals, and their Hausdorff dimensions were calculated. After Hausdorff dimension the next mostly used fractal dimension is the packing one. In [4] the authors announced explicit formulae for the packing dimensions of narrow basins and basins of certain other types. In the present paper we set forth detailed proofs for those formulae.

Let us proceed to strict definitions and statements.

Consider a finite set $X=\{1, \ldots, k\}$. In what follows this set will be called the alphabet and its elements the letters. Any sequences of letters, finite or infinite, will be called the signals. The set of finite signals of length $n$ is naturally denoted as $X^{n}$, and the set of all infinite signals as

$$
X^{\mathbb{N}}=\left\{x=\left(x_{1}, x_{2}, \ldots\right) \mid x_{i} \in X\right\} .
$$

Each initial segment of a signal will be called its prefix.

Let $M(X)$ be the set of all probability measures on $X$ :

$$
M(X)=\left\{\mu=(\mu(1), \ldots, \mu(k)) \in \mathbb{R}^{k} \mid \sum_{i} \mu(i)=1, \mu(i) \geq 0\right\} .
$$

Evidently, $M(X)$ is convex and compact. For each letter $x \in X$ denote by $\delta_{x}$ the unit measure supported at $x$, that is

$$
\delta_{x}(y)=\left\{\begin{array}{l}
1, \text { if } y=x \\
0, \text { if } y \neq x .
\end{array}\right.
$$

Every finite signal $x=\left(x_{1}, \ldots, x_{n}\right)$ generates an empirical measure $\delta_{x, n} \in M(X)$ by the rule

$$
\delta_{x, n}=\frac{\delta_{x_{1}}+\ldots+\delta_{x_{n}}}{n} .
$$

In other words, $\delta_{x, n}(y)$ is the average frequency of the letter $y$ among $x_{1}, \ldots, x_{n}$. Every infinite signal $x=\left(x_{1}, x_{2}, \ldots\right) \in X^{\mathbb{N}}$ defines a sequence of empirical measures $\delta_{x, n}$ generated by its prefixes of length $n$.

For each infinite signal $x$ denote by $V(x)$ the set of all limit points of the sequence $\delta_{x, n} \in M(X)$. In view of compactness of $M(X)$ this set is non-empty. Moreover, in [3, lemma 3] it is proved that $V(x)$ is compact and connected. 
For every subset $W \subset M(X)$ let us define the following sets in $X^{\mathbb{N}}$ : the basin $\mathrm{B}(W)$, narrow basin $\mathrm{NB}(W)$, and wide basin $\mathrm{WB}(W)$ by formulae

$$
\begin{gathered}
\mathrm{B}(W)=\left\{x \in X^{\mathbb{N}} \mid V(x) \subset W\right\}, \\
\mathrm{NB}(W)=\left\{x \in X^{\mathbb{N}} \mid V(x)=W\right\}, \\
\mathrm{WB}(W)=\left\{x \in X^{\mathbb{N}} \mid V(x) \cap W \neq \varnothing\right\} .
\end{gathered}
$$

In other words, $\mathrm{B}(W)$ denotes the set of infinite signals $x$ such that all limit points of the sequence of empirical measures $\delta_{x, n}$ belong to $W, \mathrm{NB}(W)$ denotes the collection of infinite signals $x$ such that the set of limit points of the sequence $\delta_{x, n}$ coincides with $W$, and $\mathrm{WB}(W)$ denotes the set of infinite signals $x$ such that the sequence $\delta_{x, n}$ has at least one limit point in $W$. Obviously, these basins satisfy the inclusions

$$
\mathrm{NB}(W) \subset \mathrm{B}(W) \subset \mathrm{WB}(W) .
$$

From the above mentioned compactness and connectedness of $V(x)$ it follows that a narrow basin $\mathrm{NB}(W)$ may be non-empty only in the case when the corresponding set of limit points $W$ is non-empty, compact, and connected. Conversely, in [3] it was proved that for every non-empty connected compact set $W \subset M(X)$ the narrow basin $\mathrm{NB}(W)$ is indeed non-empty. As for basins $\mathrm{B}(W)$ and $\mathrm{WB}(W)$, it is easily seen that they are non-empty for all $W \neq \varnothing$.

Every infinite signal $x$ defines uniquely the set $V(x)$. Therefore the narrow basins $\mathrm{NB}(W)$ corresponding to different limit sets $W$ do not intersect each other. Thus the entire space of infinite signals turns out to be partitioned into the narrow basins corresponding to different connected compact subsets $W \subset M(X)$. However, the basins of two other types may have non-empty intersections.

Let us fix a row of numbers $\theta=(\theta(1), \theta(2), \ldots, \theta(k)) \in(0,1)^{k}$ (one number $\theta(i)$ for each letter $i \in X$ ) and define a metric $\rho$ on the space of infinite signals $X^{\mathbb{N}}$ in the following way:

$$
\rho(x, y)=\prod_{t=1}^{n} \theta\left(x_{t}\right), \text { where } n=\inf \left\{t \mid x_{t} \neq y_{t}\right\}-1 .
$$

Here $n$ denotes the length of the largest common prefix of $x$ and $y$. If $n=0$ then we put $\rho(x, y)=1$.

Consider the function

$$
S(\mu, \theta)=\frac{\sum_{i=1}^{k} \mu(i) \ln \mu(i)}{\sum_{i=1}^{k} \mu(i) \ln \theta(i)}, \mu \in M(X) .
$$

It is easy to see that it depends continuously on $\mu$ (under the convention $0 \ln 0=0$ ).

The purpose of this paper is to prove the following two theorems declared in [4].

Theorem 1. Suppose the space $X^{\mathbb{N}}$ is equipped with metric (1). Then for any non-empty connected compact subset $W \subset M(X)$ we have the equality

where $\operatorname{dim}_{P}$ denotes the packing dimension.

$$
\operatorname{dim}_{P} \mathrm{NB}(W)=\sup _{\mu \in W} S(\mu, \theta)
$$

Theorem 2. For any non-empty subset $W \subset M(X)$ we have

$$
\begin{gathered}
\operatorname{dim}_{P} \mathrm{~B}(W)=\sup _{\mu \in W} S(\mu, \theta), \\
\operatorname{dim}_{P} \mathrm{WB}(W)=\operatorname{dim}_{P} X^{\mathbb{N}}=\sup _{\mu \in M(X)} S(\mu, \theta) .
\end{gathered}
$$

Remark. Hausdorff dimensions of the basins $\mathrm{B}(W)$ were first calculated in $[1 ; 2]$ (under the additional assumption $\sum_{i} \theta(i)=1$, which may in fact be omitted), and dimensions of the wide basins were calculated in [5]. They have the form

$$
\operatorname{dim}_{H} \mathrm{WB}(W)=\operatorname{dim}_{H} \mathrm{~B}(W)=\sup _{\mu \in W} S(\mu, \theta)
$$


Hausdorff dimensions of the narrow basins were recently calculated in [3]:

$$
\operatorname{dim}_{H} \mathrm{NB}(W)=\inf _{\mu \in W} S(\mu, \theta) .
$$

Concerning the packing dimensions of basins, as far as we know, they were not investigated by anyone earlier.

The paper has the following structure. In the section «Packing dimensions of sets and local dimensions of measures» we define the packing dimensions of sets, local dimensions of measures, and formulate a theorem about relationships between them. In the section «An upper estimate for the packing dimension of a basin» we prove an upper estimate for the packing dimension of a basin. In the section «Construction of a model set of signals» we construct a model set of signals contained in the narrow basin. In the last section «A lower estimate for the packing dimension of a narrow basin», using the local dimensions of measures, we prove a lower estimate for the packing dimension of the model set and then deduce from it theorems 1 and 2.

\section{Packing dimensions of sets and local dimensions of measures}

At first we recall definitions of packing measures and dimensions. A packing of a set $A$ in a metric space is any finite or countable collection of balls $B\left(x_{i}, r_{i}\right)$, centered at $x_{i} \in A$ and of radii $r_{i}$, such that $\rho\left(x_{i}, x_{j}\right)>r_{i}+r_{j}$ for all $i \neq j$. An $\varepsilon$-packing is a packing consisting of balls with radii not greater than $\varepsilon$.

For every $s>0$ we put

$$
C_{\varepsilon}^{s}(A)=\sup \left\{\sum_{i} r_{i}^{s} \mid \text { balls } B\left(x_{i}, r_{i}\right) \text { form an } \varepsilon \text {-packing of } A\right\} .
$$

Evidently, $C_{\varepsilon}^{S}(A)$ does not increase while $\varepsilon$ decreases, and therefore there exists a limit

$$
C^{s}(A)=\lim _{\varepsilon \rightarrow 0} C_{\varepsilon}^{s}(A)
$$

The packing measure of dimension $s$ of a set $A$ is

$$
P^{s}(A)=\inf \left\{\sum_{i} C^{s}\left(A_{i}\right) \mid \text { the sets } A_{i} \text { form a countable cover of } A\right\} \text {, }
$$

and its packing dimension is defined as

$$
\operatorname{dim}_{P} A=\inf \left\{s>0 \mid P^{s}(A)=0\right\} .
$$

Let $M$ be a metric space and $\mu$ be a Borel measure on $M$. Then the function

$$
D_{\mu}(x)=\limsup _{r \rightarrow 0+0} \frac{\ln \mu(B(x, r))}{\ln r}, x \in M,
$$

is called the upper local dimension of the measure $\mu$.

The next theorem enables to calculate the packing dimensions of sets by means of the local dimensions of measures.

Theorem 3 [6, proposition 2.3]. Suppose A is a subset of a metric space $M$. If there exists a finite Borel measure $\mu$ on $M$ such that $D_{\mu}(x) \leq s$ for all $x \in A$, then $\operatorname{dim}_{P} A \leq s$. Conversely, if $D_{\mu}(x) \geq s$ for all $x \in A$ and the outer measure $\mu^{*}(A)$ is positive, then $\operatorname{dim}_{P} A \geq s$.

\section{An upper estimate for the packing dimension of a basin}

Now for any non-empty subset $W \subset M(X)$ we prove the estimate

$$
\operatorname{dim}_{P} \mathrm{~B}(W) \leq \sup _{\mu \in W} S(\mu, \theta) .
$$

It will imply the same estimate for the packing dimension of the narrow basin $\mathrm{NB}(W)$, since the latter is contained in $\mathrm{B}(W)$.

For each infinite signal $x=\left(x_{1}, x_{2}, \ldots\right)$ and positive integer $n$ we define a cylinder $Z_{n}(x)$ as the set of all infinite signals with prefix $\left(x_{1}, \ldots, x_{n}\right)$ :

$$
\begin{aligned}
Z_{n}(x)= & \left\{y=\left(y_{1}, y_{2}, \ldots\right) \in X^{\mathbb{N}} \mid y_{1}=x_{1}, \ldots, y_{n}=x_{n}\right\} . \\
& \text { Б2Y - cmovemera ncmopur yenexa }
\end{aligned}
$$


Denote by $\left|Z_{n}(x)\right|$ its diameter with respect to metric (1). Obviously, it can be computed according to the formula

and its logarithm can be written in the form

$$
\left|Z_{n}(x)\right|=\prod_{t=1}^{n} \theta\left(x_{t}\right)
$$

$$
\ln \left|Z_{n}(x)\right|=\prod_{t=1}^{n} \ln \theta\left(x_{t}\right)=n \sum_{i=1}^{k} \delta_{x, n}(i) \ln \theta(i) .
$$

Recall that $M(X)$ consists of all probability measures on the alphabet $X=\{1, \ldots, k\}$. These measures can be interpreted as vectors $\mu=(\mu(1), \ldots, \mu(k))$ in $\mathbb{R}^{k}$. Supply the space $\mathbb{R}^{k}$ with the norm

$$
\|\mu\|=\sum_{i=1}^{k}\left|\mu_{i}\right|, \text { where } \mu=\left(\mu_{1}, \ldots, \mu_{k}\right) .
$$

It naturally defines a metric and topology on $M(X)$.

For any neighbourhood $O(\mu)$ of a measure $\mu \in M(X)$ let us define the sets

$$
X^{n}(O(\mu))=\left\{x=\left(x_{1}, \ldots, x_{n}\right) \in X^{n} \mid \delta_{x, n} \in O(\mu)\right\}, n \in \mathbb{N} .
$$

By McMillan's equipartition theorem [7, p. 51] for any measure $\mu \in M(X)$ and any $\varepsilon>0$ there exists a neighbourhood $O(\mu)$ and a number $N(\mu, \varepsilon)$ such that

$$
\operatorname{card} X^{n}(O(\mu)) \leq e^{n(h(\mu)+\varepsilon)} \text { for all } n \geq N(\mu, \varepsilon),
$$

where $h(\mu)$ is the entropy of $\mu$ defined as

$$
h(\mu)=-\sum_{i=1}^{k} \mu(i) \ln \mu(i) .
$$

Now we start to prove inequality (4). Set

$$
c_{\theta}=\min _{1 \leq i \leq k}|\ln \theta(i)| .
$$

Fix an arbitrary number $s$ satisfying the condition

and choose $\varepsilon>0$ so small that

$$
s>\sup _{\mu \in W} S(\mu, \theta),
$$

$$
\sup _{\mu \in W} S(\mu, \theta)<s-\frac{3 \varepsilon}{c_{\theta}} .
$$

Henceforth we will consider measures $\mu$ belonging to the closure $\bar{W}$ of the set $W$. For each $\mu \in \bar{W}$ choose a neighbourhood $O(\mu)$ sufficiently small to satisfy condition (7) and, in addition, such that for all measures $v \in O(\mu)$ the following inequality holds

$$
\frac{\sum_{i=1}^{k} \mu(i) \ln \mu(i)}{\sum_{i=1}^{k} v(i) \ln \theta(i)}<\frac{\sum_{i=1}^{k} \mu(i) \ln \mu(i)}{\sum_{i=1}^{k} \mu(i) \ln \theta(i)}+\frac{\varepsilon}{c_{\theta}}=S(\mu, \theta)+\frac{\varepsilon}{c_{\theta}} .
$$

Then from (8)-(10) it follows that

$$
\frac{\sum_{i=1}^{k} \mu(i) \ln \mu(i)}{\sum_{i=1}^{k} v(i) \ln \theta(i)}<s-\frac{2 \varepsilon}{c_{\theta}} \leq s+\frac{2 \varepsilon}{\sum_{i=1}^{k} v(i) \ln \theta(i)},
$$

wherefrom, after multiplication by the negative denominator, we obtain 


$$
s \sum_{i=1}^{k} v(i) \ln \theta(i)<-h(\mu)-2 \varepsilon \text { for all } v \in O(\mu) .
$$

Notice that if for some $x \in X^{\mathbb{N}}$ we have $\delta_{x, n} \in O(\mu)$ then by (5) and (11)

and hence

$$
s \ln \left|Z_{n}(x)\right|=s n \sum_{i=1}^{k} \delta_{x, n}(i) \ln \theta(i)<-n(h(\mu)+2 \varepsilon),
$$

$$
\left|Z_{n}(x)\right|^{s}<e^{-n(h(\mu)+2 \varepsilon)}
$$

Thus, for every measure $\mu \in \bar{W}$ there exists a neighbourhood $O(\mu)$ such that conditions (7), (12) hold simultaneously. Choose a finite cover $O\left(\mu_{1}\right), \ldots, O\left(\mu_{l}\right)$ of the compact set $\bar{W}$ by neighbourhoods of that type.

Consider a sequence of sets

$$
A_{N}=\left\{x \in \mathrm{B}(W) \mid \delta_{x, n} \in O\left(\mu_{1}\right) \cup \ldots \cup O\left(\mu_{l}\right) \text { for all } n \geq N\right\} .
$$

Evidently, the greater is $N$, the greater is $A_{N}$. The definition of a basin implies that for each signal $x \in \mathrm{B}(W)$ the distance from $\delta_{x, n}$ to $W$ tends to zero when $n \rightarrow \infty$. It follows that the sets $A_{N}$ form a cover of the basin $\mathrm{B}(W)$.

Take any positive integers $m, N$ satisfying the conditions

$$
m \geq N \geq \max _{1 \leq j \leq l} N\left(\mu_{j}, \varepsilon\right),
$$

where $N\left(\mu_{j}, \varepsilon\right)$ are the constants from (7) corresponding to the measures $\mu_{j}$. Consider an arbitrary packing of the set $A_{N}$ by disjoint cylinders of the form $Z_{n_{i}}\left(x_{i}\right)$, where $x_{i} \in A_{N}$ and $n_{i} \geq m$. For each $n \geq N\left(\mu_{j}\right.$, $\left.\varepsilon\right)$ the number of different cylinders $Z_{n}(x)$ such that $\delta_{x, n} \in O\left(\mu_{j}\right)$ by virtue of (6) is equal to the number of elements in the set $X^{n}\left(O\left(\mu_{j}\right)\right)$, which by (7) does not exceed $e^{n\left(h\left(\mu_{j}\right)+\varepsilon\right)}$. From here, taking into account (12) and (13), we obtain the estimate

$$
\begin{gathered}
\sum_{i}\left|Z_{n_{i}}\left(x_{i}\right)\right|^{s} \leq \sum_{n \geq m} \sum_{j=1}^{l} e^{n\left(h\left(\mu_{j}\right)+\varepsilon\right)} e^{-n\left(h\left(\mu_{j}\right)+2 \varepsilon\right)}= \\
=\sum_{n \geq m} \sum_{j=1}^{l} e^{-n \varepsilon}=\frac{l e^{-m \varepsilon}}{1-e^{-\varepsilon}} \rightarrow 0 \text { as } m \rightarrow \infty .
\end{gathered}
$$

It is easy to see that every ball $B(x, r)$ in the space of signals $X^{\mathbb{N}}$, provided $r<1$, coincides with a cylinder $Z_{n}(x)$, where $n$ is determined by the conditions $\left|Z_{n}(x)\right| \leq r<\left|Z_{n-1}(x)\right|$. Therefore every packing of $A_{N}$ by balls $B\left(x_{i}, r_{i}\right)$, where $x_{i} \in A_{N}$, in fact consists of disjoint cylinders of the form $Z_{n_{i}}\left(x_{i}\right)$, where

$$
\left|Z_{n_{i}}\left(x_{i}\right)\right| \leq r_{i}<\frac{\left|Z_{n_{i}}\left(x_{i}\right)\right|}{\min _{j} \theta(j)} .
$$

It follows from (14), (15) that $C^{s}\left(A_{N}\right)=0$. Since the sets $A_{N}$ cover $\mathrm{B}(W)$, this implies the equality $P^{s}(\mathrm{~B}(W))=0$. Hence the packing dimension of the basin $\mathrm{B}(W)$ does not exceed $s$. In view of arbitrariness of $s>\sup _{\mu \in W} S(\mu, \theta)$ we obtain (4).

\section{Construction of a model set of signals}

Let $W$ be a non-empty connected compact subset in $M(X)$. In this section we construct a model set $D_{\infty} \subset \mathrm{NB}(W)$. We will prove later on that its packing dimension coincides with the dimension of narrow basin $\mathrm{NB}(W)$ specified in theorem 1 .

All details of construction of the model set $D_{\infty}$ are explicitly described in paper [3]. We recall briefly only a general idea of the construction, omitting technical issues, which can be found in [3].

First of all, we need the following lemma. 
Lemma 4 [3, lemma 5]. Let $W$ be a non-empty connected compact subset of a metric space. Then there exists a sequence $x_{i} \in W$ such that its set of limit points coincides with $W$ and, in addition, $\rho\left(x_{i}, x_{i+1}\right) \rightarrow 0$.

By means of this lemma we choose and fix a sequence of measures $\mu_{i} \in M(X)$ such that its set of limit points coincides with $W$ and at the same time $\left\|\mu_{i}-\mu_{i+1}\right\| \rightarrow 0$. In addition, let all $\mu_{i}$ be strictly positive. This can be ensured by the replacement $\mu_{i}^{\prime}(x)=\left(1-2^{-i}\right) \mu_{i}(x)+\frac{2^{-i}}{k}$ for all $x \in X$ (where $\left.k=|X|\right)$. We preserve the prior notation $\mu_{i}$ for these corrected measures. As a result, the set of limit points of the sequence $\mu_{i}$ will not change (will coincide with $W$ ), and the condition $\left\|\mu_{i}-\mu_{i+1}\right\| \rightarrow 0$ will remain valid.

Let

$$
\begin{aligned}
C & =\max \{-\ln \theta(j) \mid j=1, \ldots, k\}, \\
C_{i} & =\max \left\{-\ln \mu_{i}(j) \mid j=1, \ldots, k\right\} .
\end{aligned}
$$

By positivity of $\mu_{i}$ all the constants $C_{i}$ are finite.

Choose a sequence of positive numbers $\varepsilon_{i}$ satisfying the condition

$$
\varepsilon_{i} \rightarrow 0, C_{i} \varepsilon_{i} \rightarrow 0 \text {, as } i \rightarrow \infty \text {. }
$$

Then construct a sequence of positive integers $n_{i}$ satisfying the condition

Using these $\varepsilon_{i}$ and $n_{i}$, define the sets

$$
n_{i+1} \geq\left(i+\frac{1}{\varepsilon_{i}}\right) n_{i} .
$$

$$
A_{i}=\left\{x \in X^{n_{i}}:\left\|\delta_{x, n_{i}}-\mu_{i}\right\|<\varepsilon_{i}\right\} \subset X^{n_{i}} .
$$

Since $\mu_{i} \in M(X)$ is a probability distribution on $X$, its Cartesian power $\mu_{i}^{n_{i}}$ is a probability distribution on $X^{n_{i}}$. The law of large numbers implies that $\mu_{i}^{n_{i}}\left(A_{i}\right) \rightarrow 1$ as $n_{i} \rightarrow \infty$. Therefore the sequence $n_{i}$ could be chosen growing so fast that along with (19) the following condition holds true:

$$
\frac{n_{i}^{-1}\left|\ln \mu_{i}^{n_{i}}\left(A_{i}\right)\right|}{\min _{j}\left|\ln \mu_{i}(j)\right|} \rightarrow 0 \text { as } i \rightarrow \infty .
$$

Finally, define the model set $D_{\infty}$ according to the formulae

$$
\begin{gathered}
D_{i}=A_{1}^{n_{2}} \times A_{2}^{n_{3}} \times \ldots \times A_{i}^{n_{i+1}}, \\
D_{\infty}=A_{1}^{n_{2}} \times A_{2}^{n_{3}} \times \ldots
\end{gathered}
$$

Lemma 5 [3, lemma 6]. Let $W$ be a non-empty connected compact subset in $M(X)$, and a sequence of strictly positive probability measures $\mu_{i} \in M(X)$ be such that its set of limit points coincides with $W$ and, at the same time, $\left\|\mu_{i}-\mu_{i+1}\right\| \rightarrow 0$. In this setting the model set $D_{\infty}$ defined in (16)-(23) has the property that for each signal $w \in D_{\infty}$ the set of limit points of the sequence $\delta_{w, n}$ coincides with $W$ (in other words, $V(w)=W$ and hence $D_{\infty} \subset \mathrm{NB}(W)$ ).

In particular, this lemma implies $\mathrm{NB}(W) \neq \varnothing$.

\section{A lower estimate for the packing dimension of a narrow basin}

In this section for the model set $D_{\infty}$ associated (as described above) with a connected compact subset $W \subset M(X)$ we will prove the estimate

Inasmuch as $D_{\infty} \subset \mathrm{NB}(W)$ it will imply that

$$
\operatorname{dim}_{P} D_{\infty} \geq \sup _{\mu \in W} S(\mu, \theta) .
$$

$$
\operatorname{dim}_{P} \mathrm{NB}(W) \geq \sup _{\mu \in W} S(\mu, \theta) .
$$


At first notice that for every finite signal $x=\left(x_{1}, \ldots, x_{n}\right) \in X^{n}$ and measure $\mu \in M(X)$, we have the relations

$$
\begin{gathered}
\mu^{n}(x)=\mu^{|x|}(x)=\prod_{i=1}^{n} \mu\left(x_{i}\right), \\
\ln \mu^{|x|}(x)=\sum_{i=1}^{n} \ln \mu\left(x_{i}\right)=|x| \sum_{j=1}^{k} \delta_{x, n}(j) \ln \mu(j), \\
\left|\ln \mu^{|x|}(x)-\right| x\left|\sum_{j=1}^{k} \mu(j) \ln \mu(j)\right| \leq|x| \cdot \| \delta_{x, n}-\mu\left|\max _{1 \leq j \leq k}\right| \ln \mu(j) \mid .
\end{gathered}
$$

For every finite signal $x=\left(x_{1}, \ldots, x_{n}\right)$ we define the cylinder $Z(x)$ consisting of all infinite signals with prefix $x$ :

$$
Z(x)=\left\{w=\left(w_{1}, w_{2}, \ldots\right) \in X^{\mathbb{N}} \mid w_{1}=x_{1}, \ldots, w_{n}=x_{n}\right\}
$$

Denote by $|Z(x)|$ its diameter with respect to metric (1). Obviously,

$$
\begin{gathered}
|Z(x)|=\prod_{i=1}^{n} \theta\left(x_{i}\right), \\
\ln |Z(x)|=\sum_{i=1}^{n} \ln \theta\left(x_{i}\right)=|x| \sum_{j=1}^{k} \delta_{x, n}(j) \ln \theta(j), \\
|\ln | Z(x)|-| x\left|\sum_{j=1}^{k} \mu(j) \ln \theta(j)\right| \leq|x| \cdot \| \delta_{x, n}-\mu\left|\max _{1 \leq j \leq k}\right| \ln \theta(j) \mid .
\end{gathered}
$$

Take the sequence of measures $\mu_{i} \in M(X)$ used in the construction of model set $D_{\infty}$ and define the following probability measure $\mu$ on $X^{\mathbb{N}}$ :

$$
\mu=\mu_{1}^{n_{1} n_{2}} \times \mu_{2}^{n_{2} n_{3}} \times \ldots
$$

For each signal $w \in X^{\mathbb{N}}$ we denote by $w^{\prime}$ its finite prefixes of arbitrary lengths. Since every ball $B(w, r) \subset X^{\mathbb{N}}$ coincides with a cylinder $Z_{n}(w)$, where $\left|Z_{n}(w)\right| \leq r<\left|Z_{n-1}(w)\right|$,

$$
D_{\mu}(x)=\limsup _{r \rightarrow 0+0} \frac{\ln \mu(B(x, r))}{\ln r}=\limsup _{\left|w^{\prime}\right| \rightarrow \infty} \frac{\ln \mu\left(Z\left(w^{\prime}\right)\right)}{\ln \left|Z\left(w^{\prime}\right)\right|} .
$$

Further we will prove the estimate

$$
\limsup _{\left|w^{\prime}\right| \rightarrow \infty} \frac{\ln \mu\left(Z\left(w^{\prime}\right)\right)}{\ln \left|Z\left(w^{\prime}\right)\right|} \geq \sup _{\mu \in W} S(\mu, \theta) \text { for all } w \in D_{\infty} .
$$

If the right-hand side in (30) vanishes then this estimate is trivial. Therefore it is sufficient to consider the case when the right-hand side in (30) is positive.

Fix an arbitrary real number $s$ satisfying the conditions

$$
0<s<\sup _{\mu \in W} S(\mu, \theta)
$$

The function $S(\mu, \theta)$ attains its maximum on the compact set $W$ at a certain point $\mu^{*} \in W$. By construction $\mu^{*}$ is a limit point for the sequence of measures $\mu_{i}$. Hence there exists an infinite subset $I \subset \mathbb{N}$ such that for all $i \in I$,

$$
S\left(\mu_{i}, \theta\right)=\frac{\sum_{j=1}^{k} \mu_{i}(j) \ln \mu_{i}(j)}{\sum_{j=1}^{k} \mu_{i}(j) \ln \theta(j)}>s
$$


and, consequently,

$$
\sum_{j=1}^{k} \mu_{i}(j) \ln \mu_{i}(j)<s \sum_{j=1}^{k} \mu_{i}(j) \ln \theta(j), i \in I .
$$

Take a number $i \in I$. Consider an arbitrary model signal $w \in D_{\infty}$. By construction it has prefix of the form $w^{\prime}=x y$, where $x \in D_{i-1}$ and $y \in A_{i}^{n_{i+1}}$.

Notice that in view of (19), (20), (22)

$$
\frac{|x|}{|y|}=\frac{n_{1} n_{2}+\ldots+n_{i-1} n_{i}}{n_{i} n_{i+1}} \leq \frac{(i-1) n_{i-1} n_{i}}{n_{i} n_{i+1}} \leq \frac{n_{i}}{n_{i+1}} \leq \varepsilon_{i} .
$$

Let us estimate the value of $\ln \mu\left(Z\left(w^{\prime}\right)\right)$. By definition (28) of $\mu$,

$$
\mu\left(Z\left(w^{\prime}\right)\right) \leq \mu_{i}^{|y|}(y) .
$$

It follows from (26) that

$$
\ln \mu_{i}^{|y|}(y) \leq|y| \sum_{j=1}^{k} \mu_{i}(j) \ln \mu_{i}(j)+|y| \cdot|| \delta_{y,|y|}-\mu_{i}\left|\max _{1 \leq j \leq k}\right| \ln \mu_{i}(j) \mid .
$$

Combining (33), (34), the inequality $\left\|\delta_{y,|y|}-\mu_{i}\right\|<\varepsilon_{i}$ (which follows from definition (20) of the set $A_{i}$ ), and equality (17), having the form $\max _{j}\left|\ln \mu_{i}(j)\right|=C_{i}$, we obtain the estimate

$$
\ln \mu\left(Z\left(w^{\prime}\right)\right) \leq \ln \mu_{i}^{|y|}(y) \leq|y| \sum_{j=1}^{k} \mu_{i}(j) \ln \mu_{i}(j)+|y| \varepsilon_{i} C_{i} .
$$

Then, substitution of (31) in (35) gives

$$
\ln \mu\left(Z\left(w^{\prime}\right)\right) \leq s|y| \sum_{j=1}^{k} \mu_{i}(j) \ln \theta(j)+|y| \varepsilon_{i} C_{i} .
$$

The product $C_{i} \varepsilon_{i}$ in view of (18) tends to zero. Therefore the second summand in the right-hand side of (36) is infinitely small with respect to the first one. So (36) can be written in the form

$$
\ln \mu\left(Z\left(w^{\prime}\right)\right) \leq s\left(|y| \sum_{j=1}^{k} \mu_{i}(j) \ln \theta(j)\right)\left(1+\alpha_{i}(w)\right), i \in I,
$$

where $\alpha_{i}(w) \rightarrow 0$ as $i \rightarrow \infty$.

In the same way we may estimate $\ln \left|Z\left(w^{\prime}\right)\right|$ from below by means of (16), (27):

$$
\ln \left|Z\left(w^{\prime}\right)\right|=\ln |Z(x)|+\ln |Z(y)| \geq-|x| C+|y| \sum_{j=1}^{k} \mu_{i}(j) \ln \theta(j)-|y| \varepsilon_{i} C .
$$

Recall that $\varepsilon_{i} \rightarrow 0$, and from (32) it follows $|x| \leq \varepsilon_{i}|y|$. Therefore the first and third summands in the right-hand side of (38) are infinitely small with respect to the second one, and so (38) can be written in the form

$$
\ln \left|Z\left(w^{\prime}\right)\right| \geq\left(|y| \sum_{j=1}^{k} \mu_{i}(j) \ln \theta(j)\right)\left(1+\beta_{i}(w)\right),
$$

where $\beta_{i}(w) \rightarrow 0$ as $i \rightarrow \infty$.

Dividing (37) by (39) and taking into account that the left and right hand sides in these inequalities are negative, we obtain

$$
\frac{\ln \mu\left(Z\left(w^{\prime}\right)\right)}{\ln \left|Z\left(w^{\prime}\right)\right|} \geq s \frac{1+\alpha_{i}(w)}{1+\beta_{i}(w)}, i \in I .
$$

It follows from here that for each model signal $w \in D_{\infty}$ and its prefixes $w^{\prime}$, 


$$
\limsup _{\left|w^{\prime}\right| \rightarrow \infty} \frac{\ln \mu\left(Z\left(w^{\prime}\right)\right)}{\ln \left|Z\left(w^{\prime}\right)\right|} \geq s .
$$

In view of arbitrariness of the number $s<\sup _{\mu \in W} S(\mu, \theta)$ the last inequality implies (30).

If $\mu\left(D_{\infty}\right)>0$ then (24) follows from (29), (30), and theorem 3. But in fact, the equality $\mu\left(D_{\infty}\right)=0$ is most likely to take place. In this case it is enough to replace the measure $\mu$ in (30) by a probability measure $v$ on $D_{\infty}$ such that for any signal $w \in D_{\infty}$,

$$
\lim _{\left|w^{\prime}\right| \rightarrow \infty} \frac{\ln v\left(Z\left(w^{\prime}\right)\right)}{\ln \mu\left(Z\left(w^{\prime}\right)\right)}=1 .
$$

To this end we define measures $v_{i}$ on the alphabet $X$ by the formula

$$
v_{i}=\frac{\mu_{i}}{\left(\mu_{i}^{n_{i}}\left(A_{i}\right)\right)^{1 / n_{i}}}
$$

and a measure $v$ on the model set $D_{\infty}=A_{1}^{n_{2}} \times A_{2}^{n_{3}} \times \ldots$ (of the same type as in (28)):

$$
v=v_{1}^{n_{1} n_{2}} \times v_{2}^{n_{2} n_{3}} \times \ldots
$$

By construction $v_{i}^{n_{i}}\left(A_{i}\right)=1$. Therefore $v\left(D_{\infty}\right)=1$. Formally $v$ is not defined outside the model set $D_{\infty}$ but it may be extended by zero if one wishes.

It follows from (21), (42) that when $i \rightarrow \infty$,

$$
\frac{\left|\ln v_{i}(j)\right|}{\left|\ln \mu_{i}(j)\right|}=\left|1-\frac{n_{i}^{-1} \ln \mu_{i}^{n_{i}}\left(A_{i}\right)}{\ln \mu_{i}(j)}\right| \rightarrow 1 \text { uniformly on } j \in X .
$$

Evidently, $\left|Z\left(w^{\prime}\right)\right| \rightarrow 0$ as $\left|w^{\prime}\right| \rightarrow \infty$. From here and (40) it follows that $\mu\left(Z\left(w^{\prime}\right)\right) \rightarrow 0$ and hence $\left|Z\left(w^{\prime}\right)\right| \rightarrow 0$ as $\left|w^{\prime}\right| \rightarrow \infty$. The last convergence along with (43) implies equality (41). Thus estimates (24), (25) are completely proved.

The union of estimates (4) and (25) looks as follows:

$$
\sup _{\mu \in W} S(\mu, \theta) \leq \operatorname{dim}_{P} \mathrm{NB}(W) \leq \operatorname{dim}_{P} \mathrm{~B}(W) \leq \sup _{\mu \in W} S(\mu, \theta),
$$

where the left inequality is proved for the connected compact subsets $W \subset M(X)$ and the right one for all non-empty subsets $W \subset M(X)$. This immediately implies theorem 1 .

To prove equality (2) from theorem 2 , it is sufficient to notice that in view of (44) for any measure $\mu^{*} \in W$ we have

and take supremum over $\mu^{*} \in W$.

$$
S\left(\mu^{*}, \theta\right) \leq \operatorname{dim}_{P} B\left(\mu^{*}\right) \leq \operatorname{dim}_{P} \mathrm{~B}(W) \leq \sup _{\mu \in W} S(\mu, \theta),
$$

Equality (3) from theorem 2 follows from (44) and the inclusions

$$
\mathrm{NB}(M(X)) \subset \mathrm{WB}(W) \subset \mathrm{B}(M(X))=X^{\mathbb{N}} .
$$

\section{Библиографические ссылки}

1. Billingsley P. Hausdorff dimension in probability theory. Illinois Journal of Mathematics. 1960;4:187-209.

2. Billingsley P. Hausdorff dimension in probability theory II. Illinois Journal of Mathematics. 1961;5:291-298.

3. Бахтин ВИ, Садок БМ. Хаусдорфовы размерности узких бассейнов в пространстве последовательностей. Tpуды Института математики. 2019;27(1-2):3-12.

4. Бахтин ВИ, Садок Б. Упаковочные размерности бассейнов в пространстве последовательностей. Доклады Национальной академии наук Беларуси. 2020;64(3):263-267. DOI: 10.29235/1561-8323-2020-64-3-263-267.

5. Bakhtin V. The McMillan theorem for colored branching processes and dimensions of random fractals. Entropy. 2014;16(12): 6624-6653. DOI: 10.3390/e16126624.

6. Falconer F. Techniques in fractal geometry. Chichester: John Wiley \& Sons; 1997. [260 p.].

7. Shiryaev AN. Probability-1. $3^{\text {rd }}$ edition. [S. 1.]: Springer; 2016. 503 p. 


\section{References}

1. Billingsley P. Hausdorff dimension in probability theory. Illinois Journal of Mathematics. 1960;4:187-209.

2. Billingsley P. Hausdorff dimension in probability theory II. Illinois Journal of Mathematics. 1961;5:291-298.

3. Bakhtin VI, Sadok BM. Hausdorff dimensions of narrow basins in the space of sequences. Proceedings of the Institute of Mathematics. 2019;27(1-2):3-12. Russian.

4. Bakhtin VI, Sadok B. [Packing dimensions of basins in the space of sequences]. Doklady Natsional'noi akademii nauk Belarusi. 2020;64(3):263-267. Russian. DOI: 10.29235/1561-8323-2020-64-3-263-267.

5. Bakhtin V. The McMillan theorem for colored branching processes and dimensions of random fractals. Entropy. 2014;16(12): 6624-6653. DOI: 10.3390/e16126624.

6. Falconer F. Techniques in fractal geometry. Chichester: John Wiley \& Sons; 1997. [260 p.].

7. Shiryaev AN. Probability-1. $3^{\text {rd }}$ edition. [S. 1.]: Springer; 2016. 503 p.

Received 20.04.2021 / revised 07.07.2021 / accepted 07.07.2021. 